\title{
Advanced Characterization Techniques Enabling Commercial Development of Accident Tolerant Fuel Cladding
}

Andrew Hoffman ${ }^{1}$, Vipul Gupta ${ }^{2}$, Michael Larsen ${ }^{2}$, Soumya Nag ${ }^{2}$, Ian Spinelli ${ }^{2}$, Daniel Ruscitto ${ }^{3}$ and Raul Rebak ${ }^{2}$

${ }^{1}$ GE Research, Niskayuna, New York, United States, ${ }^{2}$ GE Research, United States, ${ }^{3}$ Materials Organization, GE Research, Niskayuna, New York, United States

The accident at the Fukushima Daiichi nuclear plant in 2011 has created a drive for the development of accident tolerant fuels which can withstand high temperature steam transients during a loss of coolant event. Under the support of the US Department of Energy, General Electric Company (GE, consisting of GE Research, GE Hitachi, and Global Nuclear Fuel) is developing IronClad ${ }^{\mathrm{TM}}$, an FeCrAl alloy which has an excellent balance of mechanical properties and resistance to both high temperature steam oxidation and hydrothermal corrosion. While the $\mathrm{FeCrAl}$ system itself has shown great promise, work is still needed to optimize both the processing route and chemical composition. Two FeCrAl variants (C26M and APMT) are currently under investigation and we have examined the chemical/microstructural-properties relationships of both alloys. This includes mechanical and corrosion testing complimented with scanning electron microscopy (SEM), transmission electron microscopy (TEM) and associated techniques. While these two alloys represent the extreme ends of the $\mathrm{Cr}$ content spectrum being considered $(12 \mathrm{Cr}$ and $21 \mathrm{Cr}$ ), there may be a "sweet spot" chemistry not yet discovered. Thus, further exploration and optimization of these alloys is of interest.

Optimization of the FeCrAl systems includes finding a balance between mechanical properties and corrosion behavior. This tradeoff between mechanical and corrosion behavior has a variety of manifestations. One such relationship is addition of $\mathrm{Al}$ which is important for the high temperature steam oxidation resistance of these alloys due to the passive $\mathrm{Al}_{2} \mathrm{O}_{3}$ film that is formed [1]. This high temperature steam oxidation resistance is key to making these alloys accident tolerant. Al addition to the ferritic matrix, however, can also lead to a loss in ductility [2]. Therefore, grain refinement techniques need to be used to enhance the workability and performance of these alloys [3]. Thus, two processing routes are being investigated by GE: powder metallurgy hot isostatic pressing (PM-HIP) and laser powder bed fusion additive manufacturing (LPBF-AM). The PM-HIP alloy is extruded, gun drilled, and pilgered to produce the tubing. The LPBF-AM fabrication method, albeit currently in exploratory stages, is being considered for producing small, complex parts (e.g., fuel-rod end caps). SEM electron backscatter diffraction (SEMEBSD) has been key to understanding the grain structure and character of both manufacturing methods. Both techniques have shown to be effective in producing the desired overall fine-grained microstructure, however PM-HIP results in high-angle grain boundaries while LPBF-AM results in dislocation cell structures/low-angle grain boundaries (see Figure 1.). These dislocation cell structures were not removed after initial heat treatment trials and HIP treatments, but they may be beneficial for enhanced resistance to radiation effects.

One other major balancing act in $\mathrm{FeCrAl}$ alloys is the competing effects of phase stability and hydrothermal corrosion resistance in $\mathrm{Cr}$ containing ferritic alloys. $\mathrm{Cr}$ content is key to stainless alloys as it forms a protective $\mathrm{Cr}_{2} \mathrm{O}_{3}$ film [4]. In ferritic stainless alloys, however, $\alpha^{\prime}$, a Cr-enriched phase, can precipitate out during thermal aging (see Figure 2) or irradiation leading to embrittlement of the alloy [5, 6]. Increasing the $\mathrm{Cr}$ content can lead to the increased precipitation of $\alpha$ ' within the matrix, however a 
decrease in $\mathrm{Cr}$ content will lead to faster corrosion rates in water immersion environments (such as the target light water reactor applications). While lower $\mathrm{Cr}$ alloys may still have structural integrity even after long term immersion exposures, dissolution of the alloy into the reactor coolant water will cause contamination over time. In addition to the $\mathrm{Cr}$, we have also observed that $\mathrm{Al}$ and Mo may also have an impact on both the kinetics and thermodynamics of $\alpha^{\prime}$ precipitation. Through aging, hardness, and TEM experiments we have observed that while $\mathrm{Al}$ may lower the miscibility gap of the $\mathrm{FeCrAl}$ system, it may enhance the kinetics of precipitation through increased thermal vacancy concentrations as $\mathrm{Al}$ can lower the enthalpy of vacancy formation [2]. To enhance our understanding experiments are being performed for high throughput testing of diffusion multiples using a combination electron microprobe, nanoindentation, TEM, and atom probe tomography (APT). This will allow us to gain a better picture of the role each element plays in the precipitation $\alpha$ '.

With these balances in mind, GE has plans to combine historical data with high throughput testing and advanced characterization to create a predictive machine learning model for future multi-objective optimization of mechanical and environmental properties for different $\mathrm{FeCrAl}$ chemistries.

\section{Acknowledgements}

This material is based on work supported by the Department of Energy [National Nuclear Security Administration] under Award Number DE- NE0008221. The funding by GE Hitachi Nuclear and Global Nuclear Fuel Americas is gratefully acknowledged.
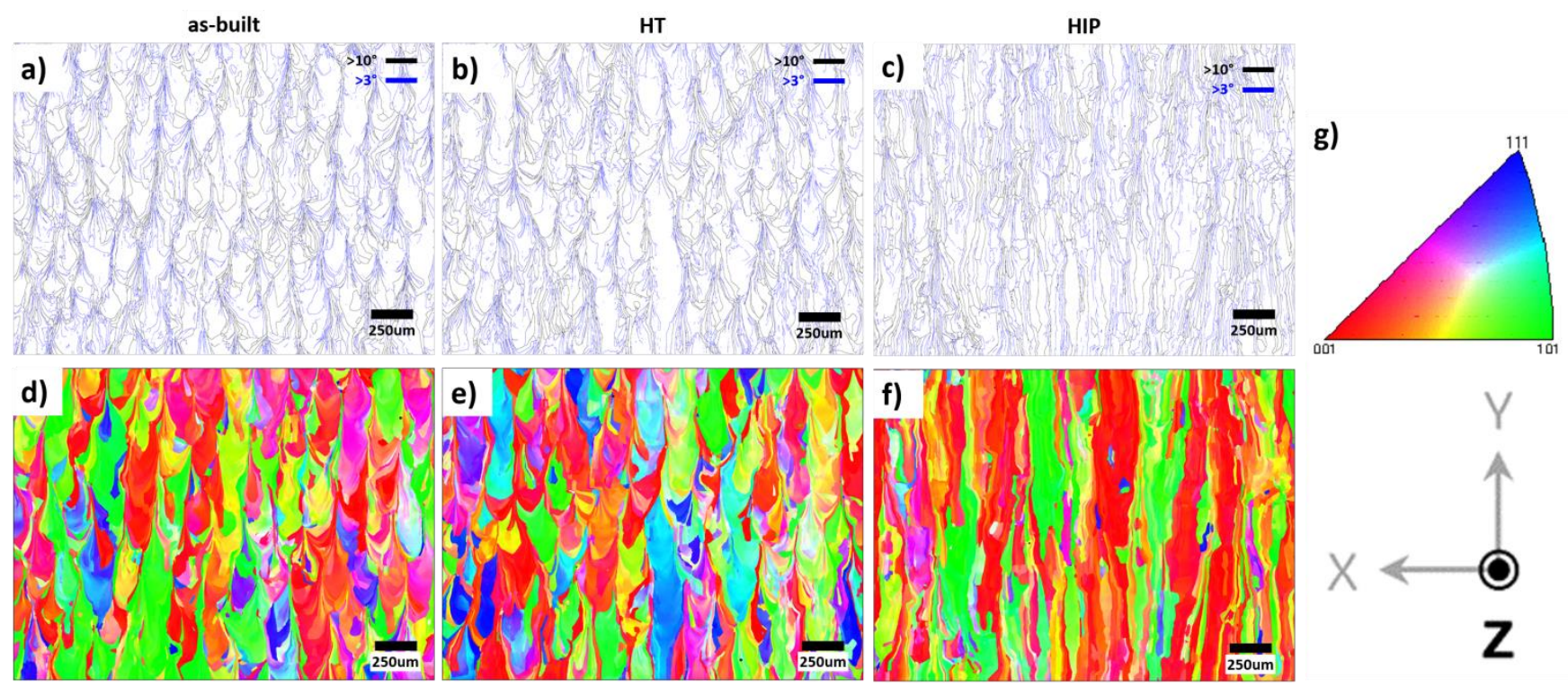

Figure 1. Figure 1. a-c) grain boundary maps and d-f) inverse pole figure (IPF) maps for a,d) as-built, b,e) heat treated, and c,f) HIPed LPBF-AM C26M obtained using electron backscatter diffraction (EBSD). g) shows the IPF map coordinate system with colored orientations displayed parallel to the z-axis. Low-angle grain boundaries/dislocation cell structures can be prominently seen in all conditions. 


\section{As-received (before HT) No alpha prime VHN $=\mathbf{3 2 5}$}
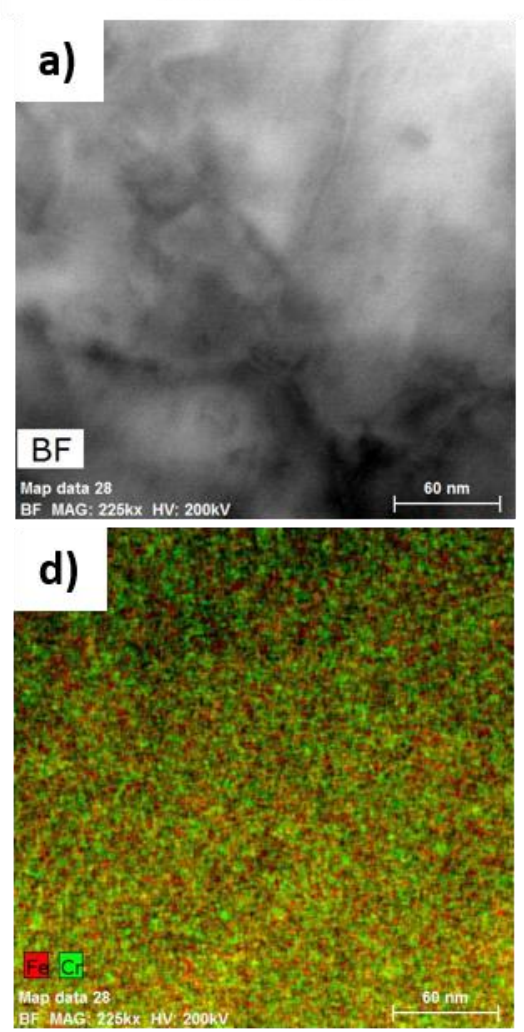

$450 \mathrm{C} / 1000 \mathrm{~h}$ Very Fine scale alpha prime $\mathrm{VHN}=\mathbf{4 2 5}$
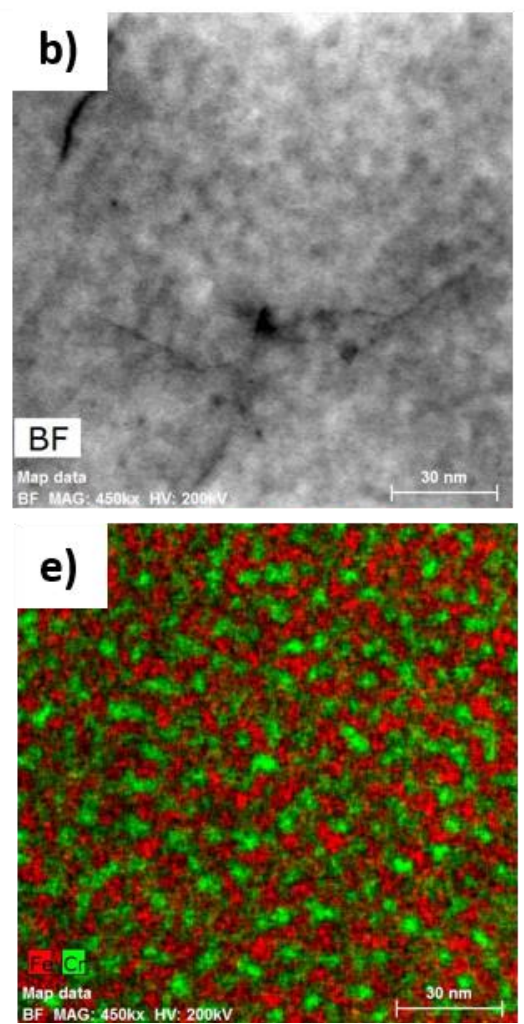

\section{$475 \mathrm{C} / 1000 \mathrm{~h}$}

Fine scale alpha prime $\mathrm{VHN}=397$
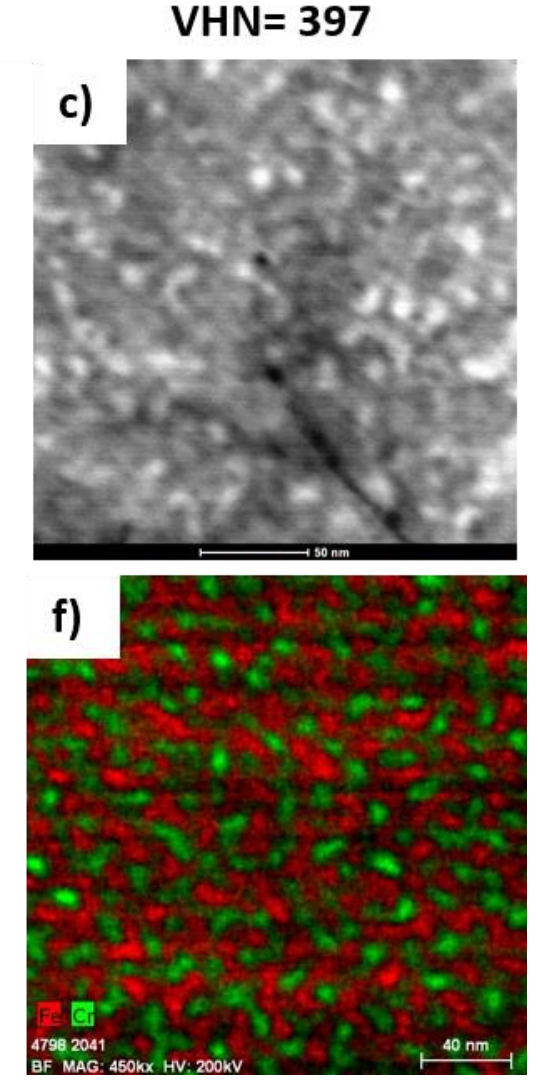

Figure 2. Figure 2. a-c) Scanning transmission electron microscope (STEM) bright field images of APMT alloys at various thermal aging conditions with $\mathrm{d}-\mathrm{f}$ ) corresponding $\mathrm{Cr} / \mathrm{Fe}$ chemical maps obtained using energy dispersive spectroscopy (EDS). a,d) show pre-aged APMT, b,e) show APMT aged at 450C for $1,000 \mathrm{~h}$ showing very fine $\alpha$ ' precipitates, and c,f) show APMT aged at $475 \mathrm{C}$ for $1,000 \mathrm{~h}$ showing fine scale $\alpha$ precipitates.

\section{References}

[1] R.B. Rebak, V.K. Gupta, M. Larsen, JOM 70 (2018) 1484-1492.

[2] J. Herrmann, G. Inden, G. Sauthoff, Acta Mater. 51 (2003) 2847-2857.

[3] X. Huang, H. Wang, S. Qiu, Y. Zhang, K. He, B. Wu, J. Mater. Process. Technol. 277 (2020) 116434.

[4] S.S. Raiman, K.G. Field, R.B. Rebak, Y. Yamamoto, K.A. Terrani, J. Nucl. Mater. 536 (2020) 152221. [5] Z. Yang, Z.X. Wang, C.H. Xia, M.H. Ouyang, J.C. Peng, H.W. Zhang, X.S. Xiao, Mater. Sci. Eng. A $772(2020) 138714$.

[6] S.A. Briggs, P.D. Edmondson, K.C. Littrell, Y. Yamamoto, R.H. Howard, C.R. Daily, K.A. Terrani, K. Sridharan, K.G. Field, Acta Mater. 129 (2017) 217-228. 